\title{
Hypothermic Oxygenated Liver Perfusion: Basic Mechanisms and Clinical Application
}

\author{
A. Schlegel • P. Kron • P. Dutkowski
}

Published online: 10 February 2015

(C) Springer International Publishing AG 2015

\begin{abstract}
Dynamic preservation strategies such as hypothermic machine perfusion are increasingly discussed to improve liver graft quality before transplantation. This review summarizes current knowledge of this perfusion technique for liver preservation. We discuss optimization of perfusion conditions and current strategies to assess graft quality during cold perfusion. Next, we provide an overview of possible pathways of protection from ischemia-reperfusion injury. Finally, we report on recent clinical applications of human hypothermic machine liver perfusion.
\end{abstract}

Keywords Hypothermic oxygenated perfusion . Ischemia-reperfusion injury $\cdot$ ROS $\cdot$ Mitochondria

$\begin{array}{ll}\text { Abbreviations } & \\ \text { CS } & \text { cold storage } \\ \text { NMP } & \text { normothermic machine perfusion } \\ \text { SNMP } & \text { subnormothermic machine perfusion } \\ \text { HMP } & \text { hypothermic machine perfusion } \\ \text { DCD } & \text { donation after cardiac death } \\ \text { ROS } & \text { reactive oxygen species } \\ \text { DAMPs } & \text { danger-associated molecular patterns } \\ \text { UW } & \text { University of Wisconsin } \\ \text { MP } & \text { machine perfusion } \\ \text { IGL-1 } & \text { Institute George Lopez-1 } \\ \text { HTK } & \text { histidine-tryptophan-ketoglutarate } \\ \text { AST } & \text { aspartate aminotransferase } \\ \text { ALT } & \text { alanine aminotransferase }\end{array}$

This article is part of the Topical Collection on Machine Preservation of the Liver

A. Schlegel · P. Kron · P. Dutkowski $(\bowtie)$

Department of Surgery and Transplantation, University Hospital

Zürich, Raemistr. 100, 8091 Zurich, Switzerland

e-mail: philipp.dutkowski@usz.ch

$\begin{array}{ll}\text { LDH } & \text { lactate dehydrogenase } \\ \text { BCL-2 protein } & \text { B cell lymphoma 2 protein } \\ \text { BH-3 } & \text { Bcl-2 homology-3 } \\ \text { BID } & \text { BH-3-interacting domain } \\ \text { BAX } & \text { Bcl-2-associated x protein } \\ \text { BAK } & \text { Bcl-2-antagonist/killer-1 } \\ \text { MPT Pore } & \text { mitochondria permeability } \\ & \text { transition pore } \\ \text { IAP binding protein } & \text { inhibitor of apoptosis protein } \\ \text { DIABLO } & \text { direct IAP-binding protein with } \\ & \text { low pI } \\ \text { AIF } & \text { apoptosis-inducing factor } \\ \text { CK 18 } & \text { cytokeratin-18 } \\ \text { DISC } & \text { death-inducing signaling complex } \\ \text { miRNA } & \text { micro-RNA } \\ \text { ER } & \text { endoplasmic reticulum } \\ \text { HMGB-1 } & \text { high-mobility group box protein 1 } \\ \text { RAGE } & \text { receptor for advanced glycation } \\ \text { TLR-4 } & \text { end products } \\ \text { LPS } & \text { roll-like receptor 4 } \\ \text { ATP } & \text { lipopolysaccharides } \\ \text { HOPE } & \text { adenosine triphosphate } \\ \text { DBD } & \text { hypothermic oxygenated perfusion } \\ & \text { donation after brain death } \\ & \end{array}$

\section{Introduction}

Nearly one century ago, Alexis Carrel and Charles Lindbergh developed the first device for automatic ex vivo perfusion of small organs at body temperature with an oxygenated solution [1]. Remarkably, despite numerous technical advances since that time, no system has been able to maintain complete function of organs (livers, kidney, lungs or hearts) for more than several days outside of the body $[2,3]$. In contrast, because of 
the simplicity and effectiveness, preservation of solid organs for transplantation has been predominantly performed by cold storage (CS) at $4{ }^{\circ} \mathrm{C}$ for the last 4 decades [4-6]. Over the past 10 years, however, the development of novel dynamic preservation techniques to improve organ quality before implantation has received increasing attention. For the liver, the main debate over machine perfusion relates to three separate approaches, differing in perfusate temperature and the degree of oxygenation: normothermic, subnormothermic and hypothermic liver perfusion. While normothermic machine perfusion (NMP) closely simulates in vivo conditions and therefore needs oxygenated diluted blood and nutritional compounds as perfusate [7-9], subnormothermic machine perfusion (SNMP) and hypothermic machine perfusion (HMP) rely on the physically dissolved oxygen in a blood-free perfusate at temperatures of $20-25^{\circ} \mathrm{C}$ (subnormothermic) $[10,11]$ or 2-10 ${ }^{\circ}$ (hypothermic) $[12,13]$.

For the purpose of this review, we will focus on the following aspects of the current research on HMP: key questions on perfusion conditions, new insights into assessing graft function during HMP, and the underlying mechanisms of protection and associated clinical applications.

\section{Perfusion Conditions}

HMP techniques for liver preservation vary significantly in experimental setups. The most common variations relate to the degree of oxygenation, the perfusion route and flow, and the perfusate composition (Tables 1 and 2) [14].

\section{Is Active Oxygenation Necessary?}

Oxygen consumption of liver tissue decreases with decreasing temperature, but does not completely stop under $\mathrm{CS}\left(4^{\circ} \mathrm{C}\right)$ [21]. Reported perfusate oxygenation during liver HMP studies ranges between 10 and $100 \mathrm{kPa}$ (Tables 1 and 2), yet the optimal level of oxygenation remains unclear. Dissolved oxygen may be sufficient at $4{ }^{\circ} \mathrm{C}$ for standard livers donated after brain death (DBD) [16]. Previous studies, however, confirm that livers exposed to warm ischemia before organ procurement, for example, donation after cardiac death (DCD) donors, have higher oxygen demands than controls [12]. It has also been shown that active oxygenation, compared to no oxygenation, is protective for DCD livers [17].

Some studies have reported oxidative stress when isolated hepatocytes are exposed to oxygen under cold conditions. This stress is due to the reaction of oxygen with increased intracellular redox-active iron ions, which triggers free radical-mediated cell injury [18]. Based on this, researchers have been reluctant to combine cold liver perfusion with oxygenation. In contrast to these reports, however, a significant number of oxygenated perfusion experiments in livers $[15,17$,
19-21] and kidneys [22] have demonstrated only minimal oxidative stress during hypothermic oxygenated perfusion despite high oxygen concentrations.

Importantly, the rate of oxygen consumption during HMP decreases rapidly during the first hour and ceases after $90 \mathrm{~min}$ at a low baseline level because of downregulation of mitochondrial respiration despite increasing ADP and sufficient levels of substrates (oxygen and electron donors) $[15,23,24]$. Accordingly, during hypothermic oxygenated liver perfusion, mitochondria switch from a high-flux electron transfer stage at the beginning of machine perfusion to a low-flux electron transfer stage during approximately 60-90 min of perfusion. Conversely, in the complete absence of oxygen, mitochondria stay in a reduced high flux state and trigger high release of mitochondrial-derived reactive oxygen species (ROS) during the first minutes of reperfusion $[25 \cdot \bullet)$. This in turn leads to the release of nuclear danger-associated molecular patterns (DAMPs) and subsequent downstream activation of nonparenchymal liver cells $[15,25 \cdot \bullet]$. Therefore, protection of liver grafts against significant oxidative stress depends on sufficient mitochondrial oxygenation during hypothermic perfusion of livers before exposure to blood and oxygen at normothermic conditions.

\section{Is low Perfusion Pressure Sufficient?}

Another aspect of the debate regarding HMP relates to the determination of the optimal perfusion pressure necessary for cold machine liver perfusion (Tables 1 and 2). Because liver sinusoids are known to be very sensitive to endothelial shear stress, a balance is needed between the perfusion of a maximum of liver cells and minimal endothelial injury. Previous work in rat livers suggests that the reduction of portal perfusion pressure to $4 \mathrm{mmHg}$ achieves both complete perfusion and no endothelial injury, while perfusion at $8 \mathrm{mmHg}$ induced endothelial injury $[15,26]$. Recent studies by our group in animal models and human livers confirm that a low portal perfusion pressure of $3 \mathrm{mmHg}$ results in complete perfusion without evidence of sinusoidal impairment $[15,27 \bullet \bullet]$. In contrast, hypothermic portal perfusion at higher pressures results in clear deterioration of endothelial cells [15]. Based on this, a significant reduction of the portal perfusion pressure to $\leq 3 \mathrm{mmHg}$ appears to have a decisive and positive effect during cold oxygenated liver perfusion and minimizes the risk of endothelial shear stress.

Is Portal Perfusion Alone Adequate in Hypothermic Conditions?

The best perfusion route during HMP has been discussed widely. Some researchers argue that simultaneous delivery 


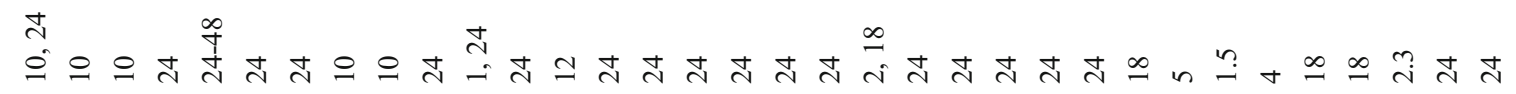

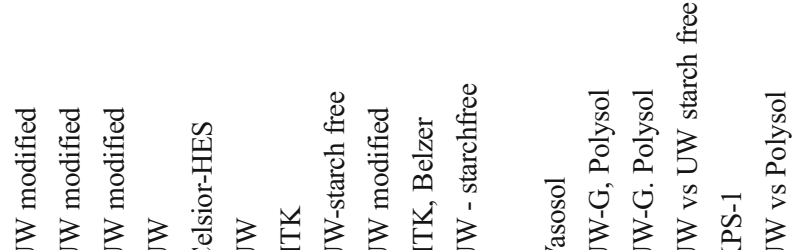

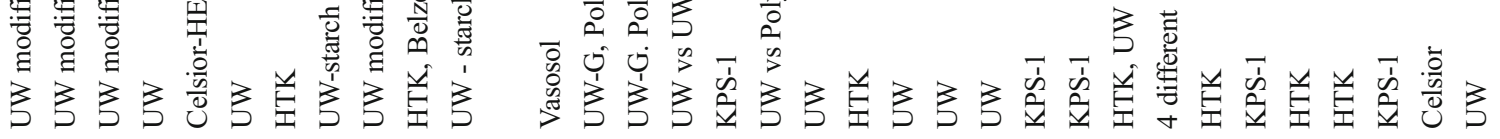

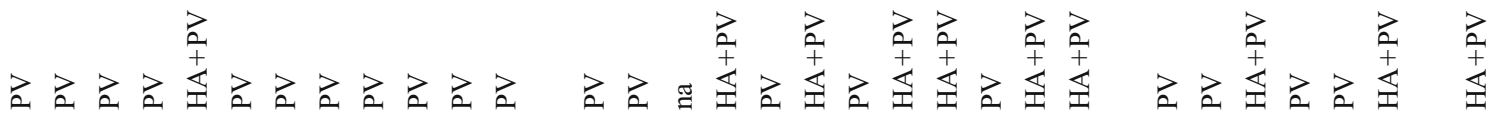

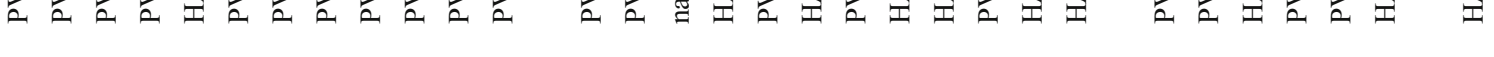

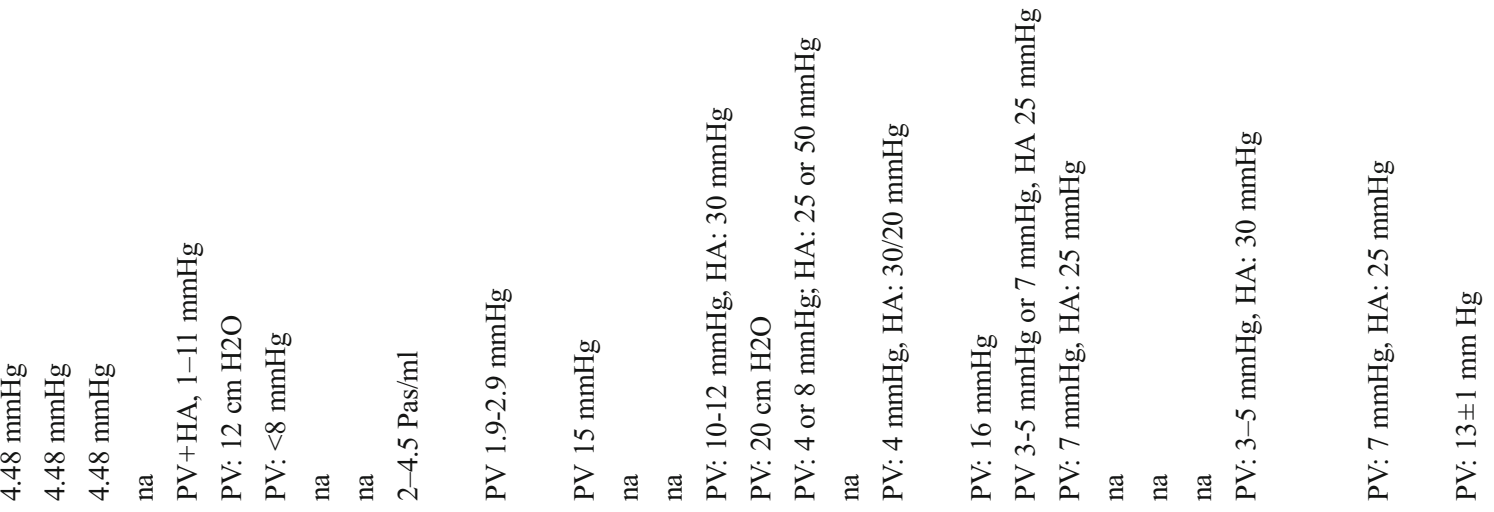

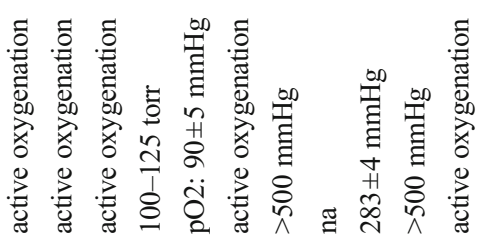

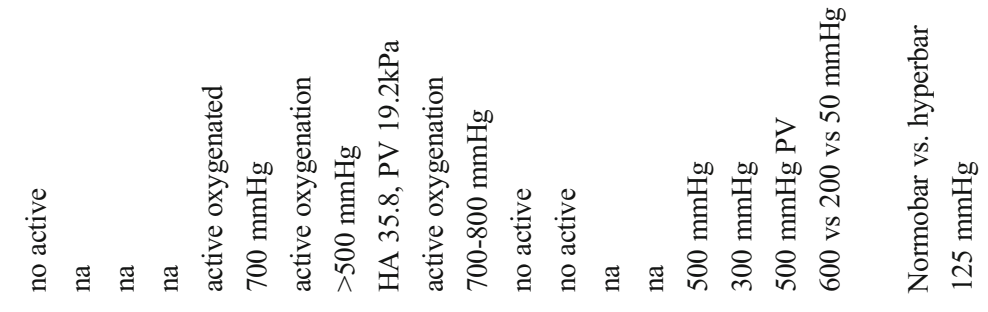

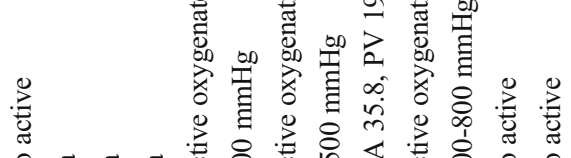

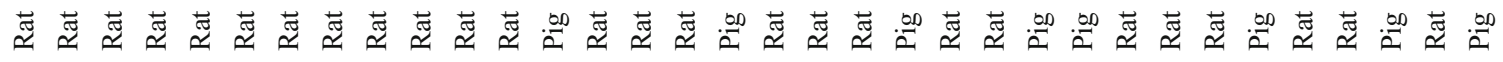

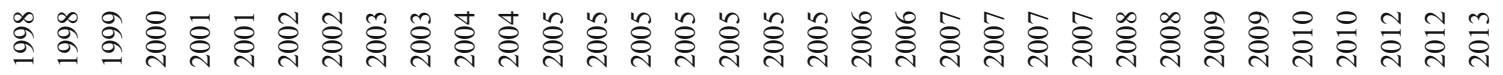

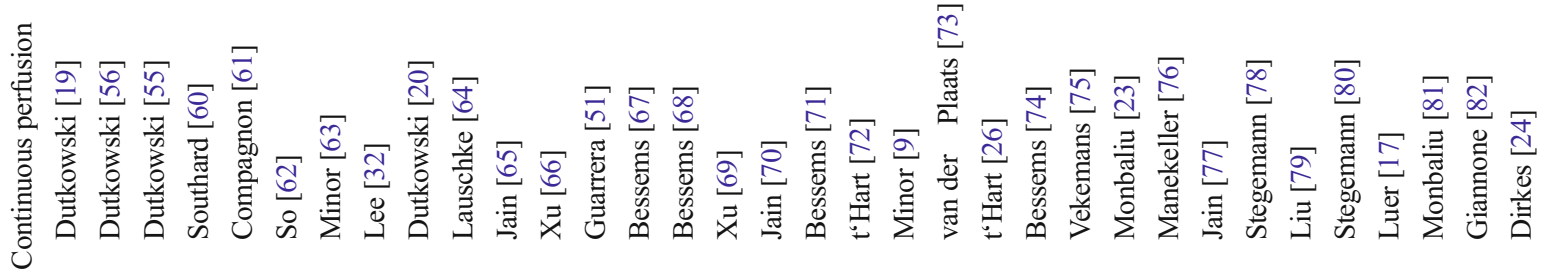




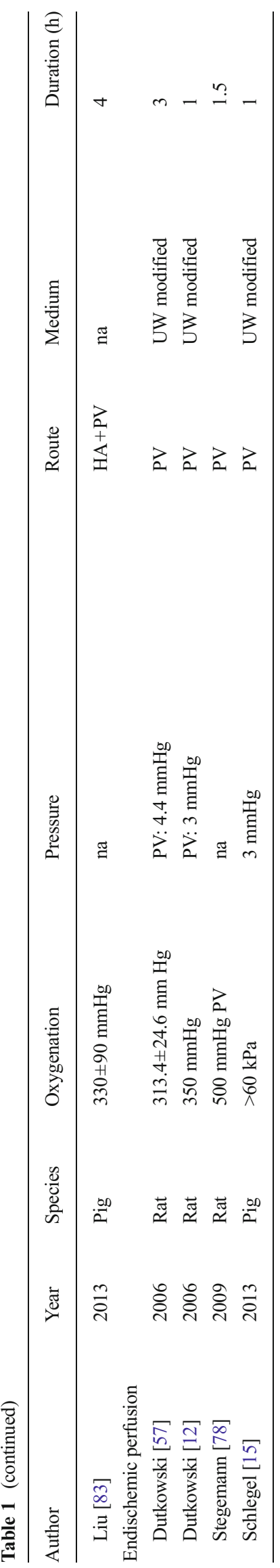

of the perfusate and oxygen through the portal vein and the hepatic artery would increase the benefit of HMP [28]. Due to the fact that portal and arterial branches join in the liver sinusoids, single portal perfusion allows for circulation to all hepatocytes in less than $1 \mathrm{~min}$ after the start of low-pressure cold perfusion in a pig model (Fig. 1). Considering the low oxygen demand of livers under cold temperatures, the supply of oxygen by single-portal perfusion appears sufficient, at least for hepatocytes, endothelial cells, Kupffer cells and intrahepatic interlobular biliary branches. Consistently, HMP in discarded human livers showed no difference in perfusion quality between singular perfusion of the portal vein or the hepatic artery alone versus dual perfusion [29]. Whether additional arterial hypothermic perfusion is useful for the viability of the extrahepatic bile ducts remains to be investigated. Recent studies suggest that most biliary injury is triggered through a cascade of mediators released during early reperfusion rather than by ischemia itself [21].

Is the Perfusion Medium Important?

The perfusates used during liver HMP in the majority of experiments are based on the original or modified UW (University of Wisconsin) solution or UW machine perfusion (MP) solution. Perfusion studies with IGL (Institut George Lopez), Celsior or HTK (Histidine-Tryptophan-Ketoglutarate) solutions have been performed (Tables 1 and 2); however, no conclusive comparison of machine liver perfusates is available. As low potassium concentrations decrease vascular resistance in hypothermia, the presence of starch increases viscosity. Therefore, solutions with low potassium and without starch appear advantageous [30], but an ideal perfusate for liver HMP has yet to be determined. Besides the fundamental implication of oxygen in the cold perfusate, additional "cleaning" effects on the sinusoidal glycocalyx are also important during liver HMP [15].

Hypothermic machine perfusion and subsequent transplantation of human livers were performed using CE-certified UW gluconate (KPS-1 ${ }^{\circledR}$, Belzer UW MP ${ }^{\circledR}$ ) or with a modification of UW gluconate including $\alpha$-ketoglutarate, L-arginine, Nacetylcysteine and prostaglandin E1 [16].

Is end-Ischemic Perfusion Effective?

End-ischemic perfusion is initiated after CS and transport of organs to the transplant center. Because transport of perfusion devices to the place of procurement is not needed, this concept is very practical and easy. In addition, recent research in rat, pig and human livers shows that despite a relatively long CS period of up to $8 \mathrm{~h}$, end-ischemic hypothermic oxygenated perfusion protects liver grafts $[12,13,15,27 \bullet \bullet, 31,32]$. This effect is the result of significant uploading of liver energy stores within a short time and the rapid conversion of 
Table 2 In vivo studies on hypothermic machine liver perfusion

\begin{tabular}{|c|c|c|c|c|c|c|c|}
\hline Author & Year & Species & Oxygenation & Pressure & Route & Medium & Duration (h) \\
\hline \multicolumn{8}{|l|}{ Continuous perfusion } \\
\hline Pienaar [3] & 1990 & Dog & na & $16-18 \mathrm{mmHg}$ & PV & UW & 72 \\
\hline Uchiyama [84] & 2001 & Pig & na & HA: $30-60 \mathrm{mmHg}$ & $\mathrm{HA}+\mathrm{PV}$ & UW-MPS & 2 \\
\hline Iwamoto [85] & 2000 & Pig & na & PV:8 mmHg, HA 20-80 mmHg & $\mathrm{HA}+\mathrm{PV}$ & na & 2 \\
\hline Lee $[13]$ & 2003 & Rat & na & na & PV & UW & 5 \\
\hline Vekemans [86] & 2009 & Pig & $310 \mathrm{mmHg}$ & na & na & $\begin{array}{l}3 \text { different } \\
\text { (KPS, Aqix-Rs1) }\end{array}$ & 4 \\
\hline Monbaliu [87] & 2011 & Pig & no active oxygenation & PV 7 mmHg, HA $30 \mathrm{mmHg}$ & $\mathrm{HA}+\mathrm{PV}$ & KPS-1 & 4 \\
\hline Fondevila [88] & 2012 & Pig & HA: $90 \mathrm{kPa}$ & $\begin{array}{l}\text { PV and HA } \\
\quad(4 \mathrm{mmHg} \text { PV, } 20-30 \mathrm{mmHg} \mathrm{HA})\end{array}$ & $\mathrm{HA}+\mathrm{PV}$ & UW MP & 4 \\
\hline \multicolumn{8}{|l|}{ Endischemic perfusion } \\
\hline de Rougemont [31] & 2009 & Pig & $>60 \mathrm{kPa}$ & $3 \mathrm{mmHg}$ & PV & UW modified & 1 \\
\hline Schlegel [21] & 2013 & Rat & $90 \mathrm{kPa}, 750 \mathrm{mmHg}$ & $3 \mathrm{mmHg}$ & PV & UW modified & 1 \\
\hline Schlegel [49•] & 2014 & Rat & $90 \mathrm{kPa}, 750 \mathrm{mmHg}$ & $3 \mathrm{mmHg}$ & PV & UW modified & 1 \\
\hline Schlegel [50] & 2014 & Rat & $90 \mathrm{kPa}, 750 \mathrm{mmHg}$ & $3 \mathrm{mmHg}$ & PV & UW modified & 1 \\
\hline
\end{tabular}

mitochondrial electron carriers from a reduced to oxidized stage [15]. Similar results have been reported by endischemic gaseous oxygen persufflation of livers and kidneys under hypothermic conditions [33, 34].

\section{Assessment of Liver Injury During Hypothermic Machine Liver Perfusion}

While several studies have analyzed organ injury during NMP [35-37], less is known about the behavior of liver grafts during HMP. Measurement of hepatocellular and mitochondrial injury during HMP provides useful information for graft assessment, but important questions remain and need to be addressed. Here we report on the current findings.

\section{Markers of Hepatocellular Injury}

Release of cytosolic hepatocyte enzymes, such as AST, ALT and LDH, is simple and can be measured in cold perfusates during liver HMP. Importantly, and as related to graft assessment, ALT release per gram of liver during HMP correlates
Fig. 1 Perfusion flow at low pressure $(3 \mathrm{mmHg})$ appears comparable for different species (rat, pig, human), if related to liver weight (A, B). Oxygen consumption during hypothermic machine liver perfusion decreases during the first hour of perfusion and stays at a low level during further perfusion $(\mathbf{C})$.

Angiography during low-pressure hypothermic perfusion of pig DCD livers demonstrates complete perfusion of all sinusoids within the first minutes by exclusively portal vein perfusion (D)

\section{A Perfusion flow}

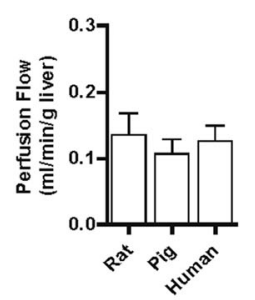

B Perfusion pressure

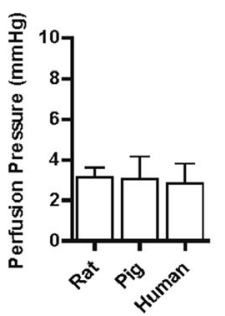

C Oxygen consumption

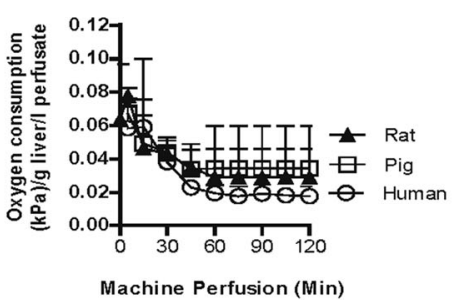

D Angiography during low pressure portal perfusion (Pig liver, donated after circulatory death)

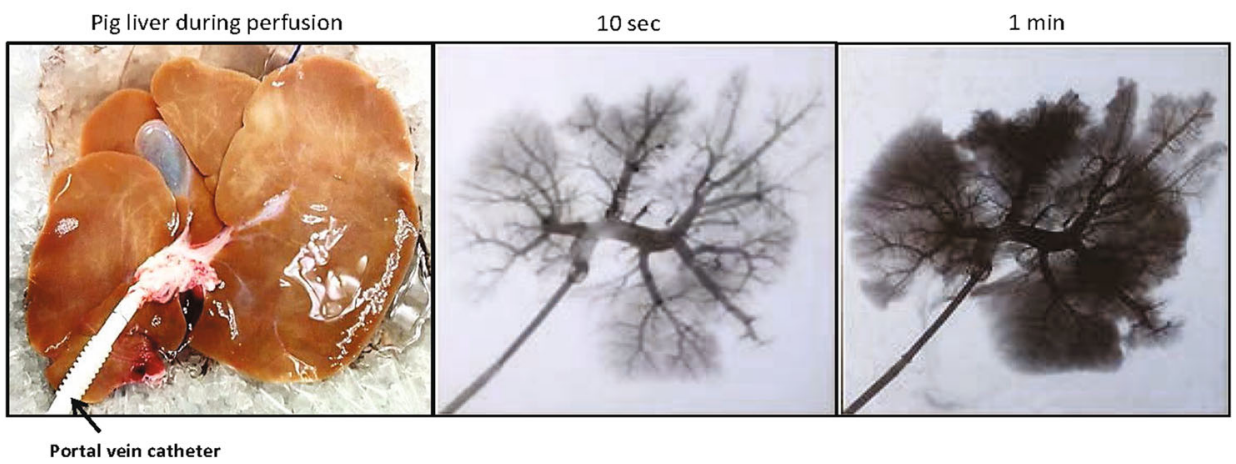


with the release of ALT during reperfusion injury after transplantation [16]. Furthermore, effluent analysis during HMP allows the determination of several acute phase reactants [38].

The soluble fraction of cytokeratin-18 (CK18), the major filament protein in the liver, has been shown to be released into the extracellular space during liver cell death. As fulllength CK19 is cleaved by caspases during apoptotic cell death, CK18 fragments are believed to present a means for monitoring epithelial apoptotic liver cell death [39•). Measurement of CK18 fragments is feasible during HMP, but future research is needed to introduce these new tests for use in regular graft assessment.

Small non-coding RNAs (21-25 nucleotides), known as microRNA (miRNA), play an important role in the regulation of gene expression. These RNAs are generated and exported from the nucleus. The most abundant liver-specific miRNA is miR-122, which is released into the circulation during hepatocyte damage [40] and is therefore detectable during HMP. Furthermore, increased miR-222 may display cholangiocyte damage and was suggested to predict cholangiopathy after liver transplantation [39•, 41, 42].

\section{Markers of Mitochondrial Injury}

Mitochondrial dysfunction causes either massive destruction of hepatocytes or sensitization of liver cells to a variety of otherwise non-lethal stress conditions. Executioner caspases and mitochondrial outer membrane permeabilization are critical for the death of hepatocytes, triggered by mitochondria [43]. The mechanisms of such mitochondria-derived injury are at least threefold:

1. Intracellular signaling: Several intracellular stress conditions are sensed by small members of the BCL-2 protein family (BH3-only proteins), which can activate mitochondrial outer membrane permeabilization by stimulating the pore-forming activity of BAX and BAK [43, 44].

2. Intramitochondrial signaling: outer membrane permeabilization can also be initiated at the inner mitochondrial membrane by an unspecific opening of the mitochondrial permeability transition pore complex (MPT-pore), resulting in the release of mitochondrial ROS and proteins, such as cytochrome $\mathrm{C}$, direct inhibitor of apoptosis-binding protein with low pI (DIABLO) and apoptosis-inducing factor (AIF) [43, 45].

3. Extracellular signaling: death receptors of the tumor necrosis factor family (Fas) are activated by extracellular signals from the Fas ligands at the cell surface. Upon binding, these receptors form the intracellular deathinducing signaling complex (DISC) and trigger either cleavage of initiator caspase 8 or activation of proapoptotic proteins (Bid, Bax), resulting in the assembly of the apoptosome complex (cytochrome c, Apaf-1, caspase 9) and activation of caspase 3 [44].

Currently, there is no experience in differentiating the distinct signaling pathways of mitochondrial injury during HMP. However, future research may allow selective determination of liver epithelial injury, mitochondrial or nuclear-derived injury by measuring CK18 fragments, special miRNAs, mitochondrial membrane proteins (cytochrome c) or apoptosisrelated proteins (SMAC, DIABLO) during cold machine liver perfusion.

\section{Ischemia Reperfusion Injury of Liver Grafts}

Mitochondrial Injury is a key Event

Efforts to restore blood flow in hypoxic tissue can paradoxically result in more destructive than beneficial effects, depending on the length of the ischemic period. Previous research indicates that the main damaging effects in ischemic reperfusion $(\mathrm{I} / \mathrm{R})$ injury involve reactions following restoration of blood flow to the tissue rather than the ischemia itself [25••). Under conditions of oxygen deficiency, oxygen molecules in the mitochondrial respiratory chain accept only one electron instead of four as accepted under normal conditions, therefore producing mitochondrial ROS (Fig. 2). The generation of ROS by mitochondria in turn triggers the MPT opening and subsequent nuclear damage and endoplasmic reticulum (ER) stress responses [25••]. Danger-associated molecular patterns (DAMPs) that are released by dying hepatocytes play a major role in this context $[15,46]$.

\section{DAMPs: Signals for Inflammation and Cell Death}

DAMPs are a group of molecules that are exposed by dying cells to operate as modulators of sterile inflammation. By binding to specific pattern-recognition receptors, DAMPs exert immune-modulatory functions with a wide panel of proinflammatory factors. The high-mobility group box-1 (HMGB1) protein is a highly conserved, abundant, non-histone nuclear protein expressed in almost all eukaryotic cells. Cellular effects of HMGB-1 are induced through signal pathway receptors, such as the receptor for advanced glycan end products (RAGE) and Toll-like receptor 4 (TLR4) [47]. Within the nucleus, HMGB-1 modulates and facilitates the transcription of many genes. Once released from cells, HMGB-1 acts as a component of the innate immune system alerting the host-tocell stress (Fig. 3). HMGB-1 is hyperacetylated upon activation with LPS in monocytes and macrophages, while unacetylated HMGB-1 is thought to be released by necrotic cells. Further hepatotoxic effects originate from a downstream 
Fig. 2 Physiological release of reactive oxygen species (ROS) occurs in mitochondria between complex II and III. During ischemia reperfusion, however, this ROS release increases significantly and can initiate opening of the mitochondrial permeability transition pore complex (MPT-pore).

Subsequently, mitochondrial proteins (cytochrome $\mathrm{C}$, Smac/DIABLO, endonuclease G, AIF) are released in the cytosol, which activate different cell organelles. Hypothermic oxygenated perfusion prevents the initial mitochondrial ROS release

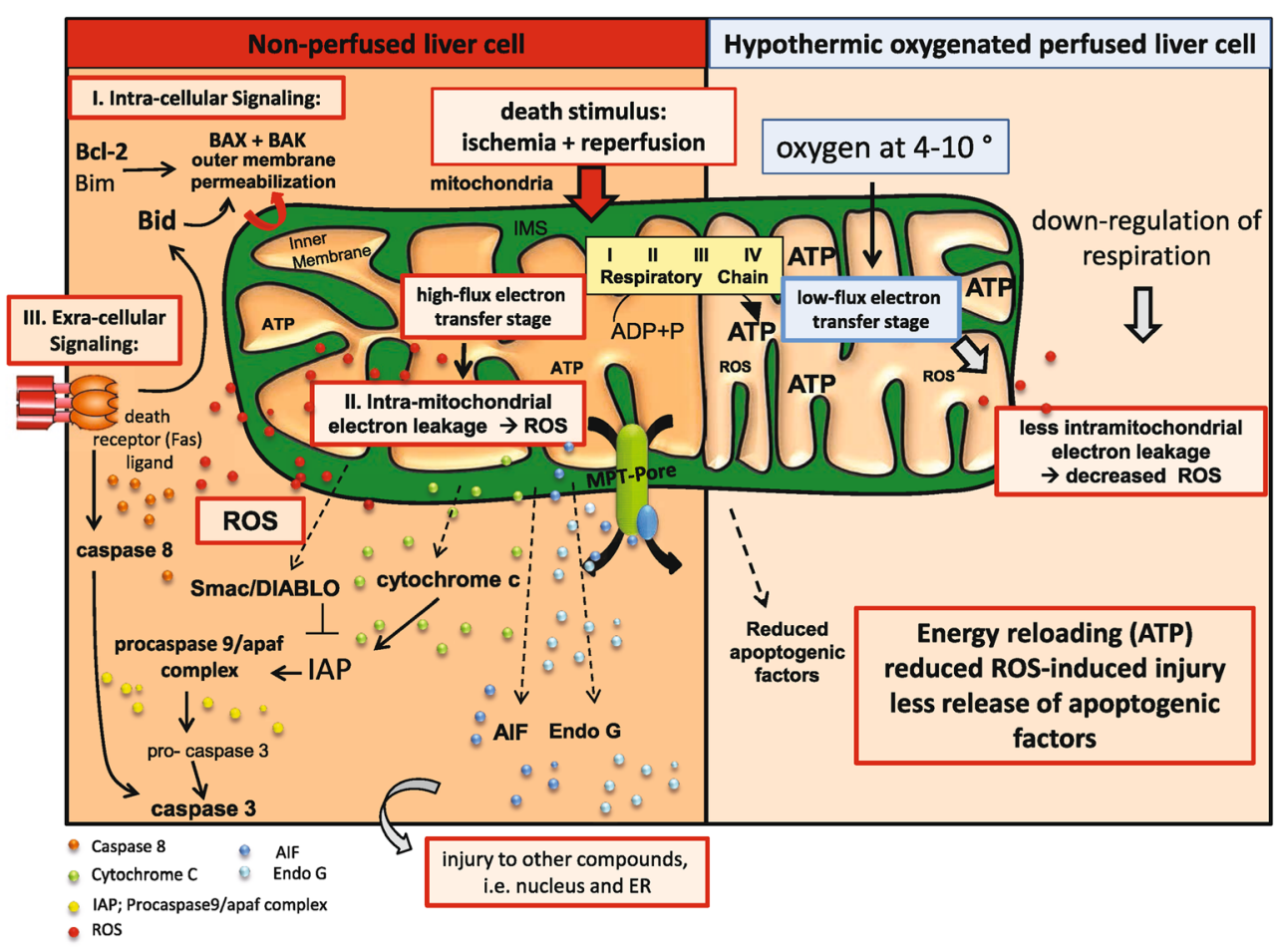

crosstalk among hepatocytes, tissue-resident immune cells (macrophages) and immune cells that are recruited to the site of injury [47].

\section{Mechanism of Protection by Hypothermic Oxygenated Perfusion}

Attenuation of Oxidative Phosphorylation Pathway

An important and unexplained finding of hypothermic oxygenated liver perfusion is the discovery that it is possible to upload depleted cellular energy stores within a short perfusion time, even after significant warm and cold ischemia. While the exact mechanism of this phenomenon remains unclear, the low energy demand in hypothermic conditions and the continuous supply of oxygen favor a positive ATP balance, despite a rapid decrease in the mitochondrial respiration rate $[15,17,48]$ (Fig. 2). Of note, hypothermic oxygenated liver perfusion is more effective in this respect as compared to normothermic oxygenated perfusion [49•].

\section{Inhibition of Mitochondria-Derived ROS and Downstream Mediators}

Hypothermic oxygenated machine perfusion changes the mitochondrial redox state by reversible suppression of oxidative metabolism, and subsequently decreases the initial ROS release during normothermic reperfusion [15]. Consequently, less mitochondrial injury triggers less release of mitochondrial ROS and therefore less nuclear injury via several pathways and results in less release of DAMPs into the circulation [46,
Fig. 3 ROS release from mitochondria leads to nuclear injury and release of dangerassociated molecular patterns (DAMPs) (A), which in turn stimulate Kupffer cells via Tolllike receptors once released by hepatocytes (B). Activated Kupffer cells release mediators and intravasal ROS $(\mathbf{C})$, which activate downstream endothelial cells and platelets (D)
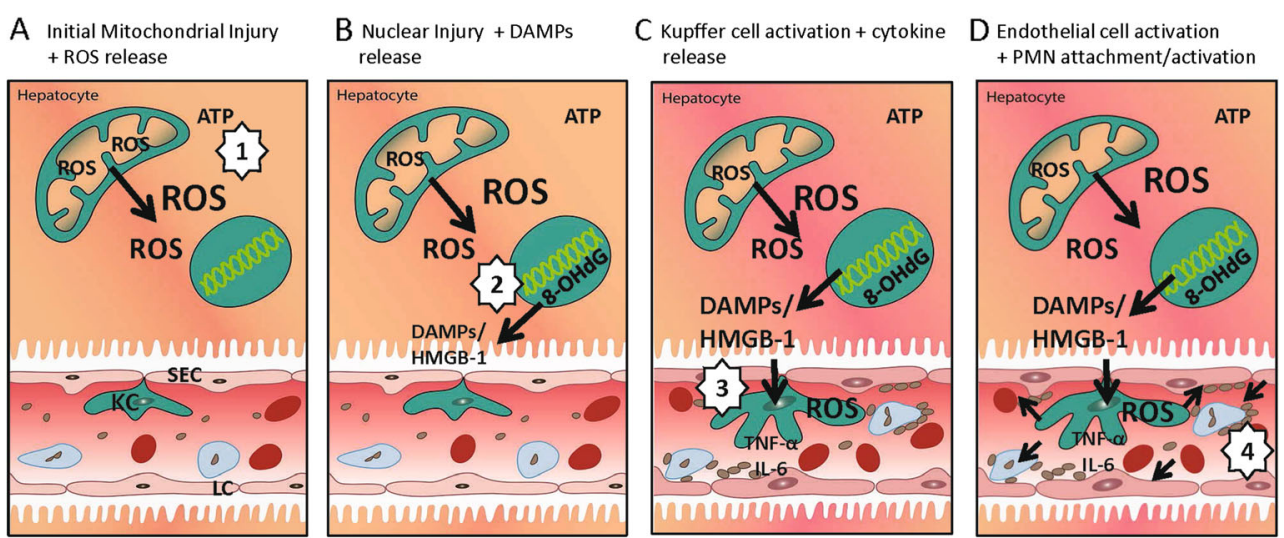
49•] (Fig. 3). In turn, Kupffer cell activation is decreased by hypothermic oxygenated perfusion with a smaller release of secondary mediators and less activation of neutrophils and platelets [25••, 49•] (Fig. 3). The effect of these reactions on the immune response ( $\mathrm{T}$ cell activation) and biliary epithelial cells has been recently reported $[21,50]$.

\section{Clinical Application of Hypothermic Liver Perfusion}

The group at Columbia University in New York first perfused ten discarded human livers for $7 \mathrm{~h}$ through the portal vein and hepatic artery without active perfusate oxygenation, using median high flow rates of $0.7 \mathrm{ml} / \mathrm{g}$ liver $/ \mathrm{min}$. Liver quality was assessed by AST release in the perfusate [51]. In a subsequent clinical study, machine-perfused livers were implanted in 20 patients, with suggested improvement in early graft function, lower serum transaminase levels and shorter hospital stay compared to a historical group of cold-stored standard liver grafts donated after brain death (DBD). The study follow-up was limited to 3 months. Of importance, while the perfusate was not actively oxygenated, measurements of $\mathrm{pO}_{2}$ levels in the perfusate confirmed no change in perfusate oxygen concentrations during the entire HMP period [16], probably because of the high perfusion flow under hypothermic conditions.

Meanwhile, this group reported on 40 machine-perfused human liver grafts from DBD donors and demonstrated reduced activation of adhesions molecules as well as less activation of leukocytes in cold-perfused livers compared to coldstored controls [52].

Two other groups [Royal Free Hospital, London [29] and KU Leuven [53] perfused discarded human livers for up to $24 \mathrm{~h}$ with an assessment of liver viability by liver enzyme release and morphology during cold perfusion. In one additional study, Vekemans et al. randomly allocated 27 discarded human livers to cold storage or hypothermic perfusion for $4 \mathrm{~h}$ (total preservation time of 15-17 h). The degree of reperfusion injury was detected during ex vivo reperfusion of all liver grafts at normal body temperature with diluted red blood cells for $2 \mathrm{~h}$, only showing reduced AST and LDH release in the perfusion group as compared to cold-stored livers, but no morphological difference could be identified [54].

Over the last decade, another technique of HMP was developed from our group, delivering a hyperbaric oxygenated perfusate $\left(>50 \mathrm{kPa} \mathrm{pO}_{2}\right)$ through the portal vein at low pressure $(<3 \mathrm{mmHg}$ ) for $1-2 \mathrm{~h}$ after a certain period of CS immediately prior to graft implantation. This perfusion technique has been tested in human DCD liver grafts [27••]. The application of this perfusion method, termed hypothermic oxygenated perfusion (HOPE), was the result of 15 years of experimental work in numerous animal models, which have shown strong protective effects, despite its short application through the portal vein only $[12,15,19,21,31,49 \cdot, 50,55-57]$. The rationale for applying such machine perfusion in DCD liver grafts was based on national ethical specifications that have prevented the procurement of grafts with less than 10 min warm ischemia after declaration of cardiac death (asystolic warm ischemia $<10 \mathrm{~min}$ ). In its inaugural clinical application, HOPE was applied consistently to eight extended human DCD liver grafts with prolonged asystolic warm ischemia periods up to $20 \mathrm{~min}$ (asystolic time) and increased donor age (median 54 years), a figure that would prevent the use of liver grafts in most centers [58, 59]. In this first human series, involving a 6-month follow-up after HOPE in DCD livers, no intrahepatic cholangiopathies were detected. Of note, and in contrast to all other perfusion strategies that need to be started at the site of procurement and require continuous pumping, this novel perfusion setting is highly simplified and low cost. Our center applied the HOPE technique in 25 human DCD livers with excellent and immediate graft function in all cases and no evidence of intrahepatic biliary injury in spite of long donor warm ischemia.

\section{Conclusions}

HMP can protect liver grafts exposed to warm and cold ischemia. This effect is probably linked closely to changes in mitochondrial electron transfer rates during cold machine perfusion and therefore depends on the abundance of oxygen during perfusion. Short-term (1-2 h) perfusion appears as effective as longer perfusion $(10 \mathrm{~h})$. Application of end-ischemic hypothermic oxygenated perfusion in human DCD livers was well tolerated in recent transplant series. Randomized trials are needed to further assess the full protective action of liver HMP, in particular with respect to biliary complications after liver transplantation.

\section{Compliance with Ethics Guidelines}

Conflict of Interest A. Schlegel, P. Kron and P. Dutkowski declare that they have no conflict of interest.

Human and Animal Rights and Informed Consent This article does not contain any studies with human or animal subjects performed by any of the authors.

\section{References}

Papers of particular interest and published recently are highlighted below as:

- Of importance

•. Of major importance

1. Dutkowski P, de Rougemont O, Clavien PA. Alexis Carrel: genius, innovator and ideologist. Am J Transplant. 2008;8(10):1998. 
2. Yamamoto N, Konishi Y, Wakashiro S, et al. Seventy-two-hour preservation of porcine liver by continuous hypothermic perfusion with UW solution in comparison with simple cold storage. J Surg Res. 1991;51(4):288.

3. Pienaar BH, Lindell SL, Van Gulik T, Southard JH, Belzer FO. Seventy-two-hour preservation of the canine liver by machine perfusion. Transplantation. 1990;49(2):258.

4. D'Alessandro AM, Kalayoglu M, Sollinger HW, et al. Experience with Belzer UW cold storage solution in human liver transplantation. Transplant Proc. 1990;22(2):474.

5. Isemer FE, Ludwig A, Schunck O, Bretschneider HJ, Peiper HJ. Kidney procurement with the HTK solution of Bretschneider. Transplant Proc. 1988;20(5):885.

6. Menasche P, Termignon JL, Pradier F, et al. Experimental evaluation of Celsior, a new heart preservation solution. Eur J Cardiothorac Surg. 1994;8(4):207.

7. Brockmann J, Reddy S, Coussios C, et al. Normothermic perfusion: a new paradigm for organ preservation. Ann Surg. 2009;250(1):1.

8. Fondevila C, Hessheimer AJ, Maathuis MH, et al. Superior preservation of DCD livers with continuous normothermic perfusion. Ann Surg. 2011;254(6):1000.

9. op den Dries S, Karimian N, Sutton ME, et al. Ex vivo normothermic machine perfusion and viability testing of discarded human donor livers. Am J Transplant. 2013;13(5):1327.

10. Tolboom H, Izamis ML, Sharma N, et al. Subnormothermic machine perfusion at both 20 degrees $\mathrm{C}$ and 30 degrees $\mathrm{C}$ recovers ischemic rat livers for successful transplantation. J Surg Res. 2012;175(1):149.

11. Bruinsma BG, Yeh H, Ozer S, et al. Subnormothermic machine perfusion for ex vivo preservation and recovery of the human liver for transplantation. Am J Transplant. 2014;14(6):1400.

12. Dutkowski P, Furrer K, Tian Y, Graf R, Clavien PA. Novel shortterm hypothermic oxygenated perfusion (HOPE) system prevents injury in rat liver graft from non-heart beating donor. Ann Surg. 2006;244(6):968.

13. Lee CY, Jain S, Duncan HM, et al. Survival transplantation of preserved non-heart-beating donor rat livers: preservation by hypothermic machine perfusion. Transplantation. 2003;76(10):1432.

14. Graham JA, Guarrera JV. "Resuscitation" of marginal liver allografts for transplantation with machine perfusion technology. J Hepatol. 2014;61(2):418.

15. Schlegel A, Rougemont O, Graf R, Clavien PA, Dutkowski P. Protective mechanisms of end-ischemic cold machine perfusion in DCD liver grafts. J Hepatol. 2013;58(2):278.

16. Guarrera JV, Henry SD, Samstein B, et al. Hypothermic machine preservation in human liver transplantation: the first clinical series. Am J Transplant. 2010;10(2):372.

17. Luer B, Koetting M, Efferz P, Minor T. Role of oxygen during hypothermic machine perfusion preservation of the liver. Transpl Int. 2010;23(9):944.

18. Rauen U, Petrat F, Li T, De Groot H. Hypothermia injury/coldinduced apoptosis-evidence of an increase in chelatable iron causing oxidative injury in spite of low $\mathrm{O} 2-/ \mathrm{H} 2 \mathrm{O} 2$ formation. FASEB J. 2000;14(13): 1953.

19. Dutkowski P, Schonfeld S, Odermatt B, Heinrich T, Junginger T. Rat liver preservation by hypothermic oscillating liver perfusion compared to simple cold storage. Cryobiology. 1998;36(1):61.

20. Dutkowski P, Krug A, Krysiak M, Dunschede F, Seifert JK, Junginger T. Detection of mitochondrial electron chain carrier redox status by transhepatic light intensity during rat liver reperfusion. Cryobiology. 2003;47(2):125.

21. Schlegel A, Graf R, Clavien PA, Dutkowski P. Hypothermic oxygenated perfusion (HOPE) protects from biliary injury in a rodent model of DCD liver transplantation. J Hepatol. 2013;59(5):984.

22. Hoyer DP, Gallinat A, Swoboda S, et al. Influence of oxygen concentration during hypothermic machine perfusion on porcine kidneys from donation after circulatory death. Transplantation. 2014;98(9):944.

23. Monbaliu D, Vekemans K, De Vos R, et al. Hemodynamic, biochemical, and morphological characteristics during preservation of normal porcine livers by hypothermic machine perfusion. Transplant Proc. 2007;39(8):2652.

24. Dirkes MC, Post IC, Heger M, van Gulik TM. A novel oxygenated machine perfusion system for preservation of the liver. Artif Organs. 2013;37(8):719.

25.• van Golen RF, van Gulik TM, Heger M. Mechanistic overview of reactive species-induced degradation of the endothelial glycocalyx during hepatic ischemia/reperfusion injury. Free Radic Biol Med. 2012;52(8):1382. This is an excellent review on ischemia and reperfusion injury involving all cellular and subcellular compounds.

26. t'Hart NA, der van Plaats A, Leuvenink HG, et al. Determination of an adequate perfusion pressure for continuous dual vessel hypothermic machine perfusion of the rat liver. Transpl Int. 2007;20(4):343.

27.• Dutkowski P, Schlegel A, de Oliveira M, Mullhaupt B, Neff F, Clavien PA. HOPE for human liver grafts obtained from donors after cardiac death. J Hepatol. 2014;60(4):765. This is the first report on hypothermic perfusion of human DCD liver grafts.

28. Op den Dries S, Sutton ME, Karimian N, et al. Hypothermic oxygenated machine perfusion prevents arteriolonecrosis of the peribiliary plexus in pig livers donated after circulatory death. PLoS One. 2014;9(2):e88521.

29. Jomaa A, Gurusamy K, Siriwardana PN, et al. Does hypothermic machine perfusion of human donor livers affect risks of sinusoidal endothelial injury and microbial infection? A feasibility study assessing flow parameters, sterility, and sinusoidal endothelial ultrastructure. Transplant Proc. 2013;45(5):1677.

30. Schlegel A, Dutkowski P. Role of hypothermic machine perfusion in liver transplantation. Transpl Int. 2014.

31. de Rougemont $\mathrm{O}$, Breitenstein S, Leskosek B, et al. One hour hypothermic oxygenated perfusion (HOPE) protects nonviable liver allografts donated after cardiac death. Ann Surg. 2009;250(5):674.

32. Lee CY, Zhang JX, Jones Jr JW, Southard JH, Clemens MG. Functional recovery of preserved livers following warm ischemia: improvement by machine perfusion preservation. Transplantation. 2002;74(7):944.

33. Minor T, Koetting M, Kaiser G, Efferz P, Luer B, Paul A. Hypothermic reconditioning by gaseous oxygen improves survival after liver transplantation in the pig. Am J Transplant. 2011;11(12): 2627.

34. Minor T, Efferz P, Luer B. Hypothermic reconditioning by gaseous oxygen persufflation after cold storage of porcine kidneys. Cryobiology. 2012;65(1):41.

35. Butler AJ, Rees MA, Wight DG, et al. Successful extracorporeal porcine liver perfusion for $72 \mathrm{hr}$. Transplantation. 2002;73(8):1212.

36. Imber CJ, St Peter SD. Lopez de Cenarruzabeitia I, et al. Advantages of normothermic perfusion over cold storage in liver preservation. Transplantation. 2002;73(5):701.

37. Sutton ME. Op den Dries S, Karimian N, et al. Criteria for Viability Assessment of Discarded Human Donor Livers during Ex Vivo Normothermic Machine Perfusion. PLoS One. 2014;9(11): e110642.

38. Tulipan JE, Stone J, Samstein B, et al. Molecular expression of acute phase mediators is attenuated by machine preservation in human liver transplantation: preliminary analysis of effluent, serum, and liver biopsies. Surgery. 2011;150(2):352.

39. Eguchi A, Wree A, Feldstein AE. Biomarkers of liver cell death. J Hepatol. 2014;60(5):1063. This review reports on biomarkers discharged from different cellular compounds who are involved in the process of cell death.

40. Steer CJ, Subramanian S. Circulating microRNAs as biomarkers: a new frontier in diagnostics. Liver Transpl. 2012;18(3):265. 
41. Verhoeven CJ, Farid WR, de Ruiter PE, et al. MicroRNA profiles in graft preservation solution are predictive of ischemic-type biliary lesions after liver transplantation. J Hepatol. 2013;59(6):1231.

42. Farid WR, Pan Q, van der Meer AJ, et al. Hepatocyte-derived microRNAs as serum biomarkers of hepatic injury and rejection after liver transplantation. Liver Transpl. 2012;18(3):290.

43. Saelens X, Festjens N, Vande Walle L, van Gurp M, van Loo G, Vandenabeele P. Toxic proteins released from mitochondria in cell death. Oncogene. 2004;23(16):2861.

44. Arnoult D, Gaume B, Karbowski M, Sharpe JC, Cecconi F, Youle RJ. Mitochondrial release of AIF and EndoG requires caspase activation downstream of Bax/Bak-mediated permeabilization. EMBO J. 2003;22(17):4385.

45. van Gurp M, Festjens N, van Loo G, Saelens X, Vandenabeele P. Mitochondrial intermembrane proteins in cell death. Biochem Biophys Res Commun. 2003;304(3):487.

46. Tang D, Kang R, Zeh 3rd HJ, Lotze MT. High-mobility group box 1, oxidative stress, and disease. Antioxid Redox Signal. 2011;14(7): 1315.

47. van Golen RF, van Gulik TM, Heger M. The sterile immune response during hepatic ischemia/reperfusion. Cytokine Growth Factor Rev. 2012;23(3):69.

48. van Golen RF, Reiniers MJ, van Gulik TM, Heger M. Organ cooling in liver transplantation and resection: How low should we go? Hepatology. 2014.

49. Schlegel A, Kron P, Graf R, Dutkowski P, Clavien PA. Warm vs. cold perfusion technique to rescue rodent liver grafts. J Hepatol. 2014. This study provides the first comparison of hypothermic and normothermic perfusion in a model of DCD rat liver transplantation.

50. Schlegel A, Kron P, Graf R, Clavien PA, Dutkowski P. Hypothermic Oxygenated Perfusion (HOPE) Downregulates the Immune Response in a Rat Model of Liver Transplantation. Ann Surg. 2014;260(5):931

51. Guarrera JV, Estevez J, Boykin J, et al. Hypothermic machine perfusion of liver grafts for transplantation: technical development in human discard and miniature swine models. Transplant Proc. 2005;37(1):323.

52. Henry SD, Nachber E, Tulipan J, et al. Hypothermic machine preservation reduces molecular markers of ischemia/reperfusion injury in human liver transplantation. Am J Transplant. 2012;12(9):2477.

53. Monbaliu D, Liu Q, Libbrecht L, et al. Preserving the morphology and evaluating the quality of liver grafts by hypothermic machine perfusion: a proof-of-concept study using discarded human livers. Liver Transpl. 2012;18(12):1495.

54. Vekemans K, van Pelt J, Komuta M, et al. Attempt to rescue discarded human liver grafts by end ischemic hypothermic oxygenated machine perfusion. Transplant Proc. 2011;43(9): 3455 .

55. Dutkowski P, Schonfeld S, Heinrich T, et al. Reduced oxidative stress during acellular reperfusion of the rat liver after hypothermic oscillating perfusion. Transplantation. 1999;68(1):44.

56. Dutkowski P, Odermatt B, Heinrich T, et al. Hypothermic oscillating liver perfusion stimulates ATP synthesis prior to transplantation. J Surg Res. 1998;80(2):365.

57. Dutkowski P, Graf R, Clavien PA. Rescue of the cold preserved rat liver by hypothermic oxygenated machine perfusion. Am J Transplant. 2006;6(5 Pt 1):903.

58. Hong JC, Yersiz H, Kositamongkol P, et al. Liver transplantation using organ donation after cardiac death: a clinical predictive index for graft failure-free survival. Arch Surg. 2011;146(9):1017.

59. Taner CB, Bulatao IG, Perry DK, et al. Asystole to cross-clamp period predicts development of biliary complications in liver transplantation using donation after cardiac death donors. Transpl Int. 2012;25(8):838.
60. Southard JH, Lindell S, Ametani M, Richer JP, Vos AW. Kupffer cell activation in liver preservation: cold storage vs machine perfusion. Transplant Proc. 2000;32(1):27.

61. Compagnon P, Clement B, Campion JP, Boudjema K. Effects of hypothermic machine perfusion on rat liver function depending on the route of perfusion. Transplantation. 2001;72(4):606.

62. So PW, Fuller BJ. A comparison of the metabolic effects of continuous hypothermic perfusion or oxygenated persufflation during hypothermic storage of rat liver. Cryobiology. 2001;43(3):238.

63. Minor T, Olschewski P, Tolba RH, Akbar S, Kocalkova M, Dombrowski F. Liver preservation with HTK: salutary effect of hypothermic aerobiosis by either gaseous oxygen or machine perfusion. Clin Transplant. 2002;16(3):206.

64. Lauschke H, Olschewski P, Tolba R, Schulz S, Minor T. Oxygenated machine perfusion mitigates surface antigen expression and improves preservation of predamaged donor livers. Cryobiology. 2003;46(1):53.

65. Jain S, Xu H, Duncan H, et al. Ex-vivo study of flow dynamics and endothelial cell structure during extended hypothermic machine perfusion preservation of livers. Cryobiology. 2004;48(3):322.

66. Xu H, Lee CY, Clemens MG, Zhang JX. Pronlonged hypothermic machine perfusion preserves hepatocellular function but potentiates endothelial cell dysfunction in rat livers. Transplantation. 2004;77(11):1676.

67. Bessems M, Doorschodt BM, van Vliet AK, van Gulik TM Machine perfusion preservation of the non-heart-beating donor rat livers using polysol, a new preservation solution. Transplant Proc. 2005;37(1):326

68. Bessems M, Doorschodt BM, Hooijschuur O, van Vliet AK, van Gulik TM. Optimization of a new preservation solution for machine perfusion of the liver: which is the preferred colloid? Transplant Proc. 2005;37(1):329.

69. Xu H, Zhang JX, Jones JW, Southard JH, Clemens MG, Lee CY. Hypothermic machine perfusion of rat livers preserves endothelial cell function. Transplant Proc. 2005;37(1):335.

70. Jain S, Lee CY, Baicu S, et al. Hepatic function in hypothermically stored porcine livers: comparison of hypothermic machine perfusion vs cold storage. Transplant Proc. 2005;37(1):340.

71. Bessems M, Doorschodt BM, van Vliet AK, van Gulik TM. Improved rat liver preservation by hypothermic continuous machine perfusion using polysol, a new, enriched preservation solution. Liver Transpl. 2005;11(5):539.

72. t'Hart NA, van der Plaats A, Leuvenink HG, et al. Hypothermic machine perfusion of the liver and the critical balance between perfusion pressures and endothelial injury. Transplant Proc. 2005;37(1):332

73. van der Plaats A, Maathuis MH, NA TH, et al. The Groningen hypothermic liver perfusion pump: functional evaluation of a new machine perfusion system. Ann Biomed Eng. 2006;34(12):1924.

74. Bessems M, Doorschodt BM, Kolkert JL, et al. Preservation of steatotic livers: a comparison between cold storage and machine perfusion preservation. Liver Transpl. 2007;13(4):497.

75. Vekemans K, Liu Q, Brassil J, Komuta M, Pirenne J, Monbaliu D. Influence of flow and addition of oxygen during porcine liver hypothermic machine perfusion. Transplant Proc. 2007;39(8):2647.

76. Manekeller S, Schuppius A, Stegemann J, Hirner A, Minor T. Role of perfusion medium, oxygen and rheology for endoplasmic reticulum stress-induced cell death after hypothermic machine preservation of the liver. Transpl Int. 2008;21(2):169.

77. Jain S, Lee SH, Korneszczuk K, et al. Improved preservation of warm ischemic livers by hypothermic machine perfusion with supplemented University of Wisconsin solution. J Invest Surg. 2008;21(2):83.

78. Stegemann J, Minor T. Energy charge restoration, mitochondrial protection and reversal of preservation induced liver injury by 
hypothermic oxygenation prior to reperfusion. Cryobiology. 2009;58(3):331.

79. Liu Q, Vekemans K, van Pelt J, et al. Discriminate liver warm ischemic injury during hypothermic machine perfusion by proton magnetic resonance spectroscopy: a study in a porcine model. Transplant Proc. 2009;41(8):3383.

80. Stegemann J, Hirner A, Rauen U, Minor T. Use of a new modified HTK solution for machine preservation of marginal liver grafts. J Surg Res. 2010;160(1):155.

81. Monbaliu DR, Debbaut C, Hillewaert WJ, et al. Flow competition between hepatic arterial and portal venous flow during hypothermic machine perfusion preservation of porcine livers. Int J Artif Organs. 2012;35(2):119.

82. Giannone FA, Trere D, Domenicali M, et al. An innovative hyperbaric hypothermic machine perfusion protects the liver from experimental preservation injury. ScientificWorldJournal. 2012;2012:573410.

83. Liu Q, Vekemans K, Iania L, et al. Assessing warm ischemic injury of pig livers at hypothermic machine perfusion. J Surg Res. 2013.
84. Uchiyama M, Matsuno N, Hama K, et al. Comparison between nonpulsatile and pulsatile machine perfusion preservation in liver transplantation from non-heart-beating donors. Transplant Proc. 2001;33(1-2):936.

85. Iwamoto H, Matsuno N, Narumi Y, et al. Beneficial effect of machine perfusion preservation on liver transplantation from nonheart-beating donors. Transplant Proc. 2000;32(7):1645.

86. Vekemans K, Liu Q, Heedfeld V, et al. Hypothermic Liver Machine Perfusion With EKPS-1 Solution vs Aqix RS-I Solution: In Vivo Feasibility Study in a Pig Transplantation Model. Transplant Proc. 2009;41(2):617.

87. Monbaliu D, Heedfeld V, Liu Q, et al. Hypothermic machine perfusion of the liver: is it more complex than for the kidney? Transplant Proc. 2011;43(9):3445.

88. Fondevila C, Hessheimer AJ, Maathuis MH, et al. Hypothermic oxygenated machine perfusion in porcine donation after circulatory determination of death liver transplant. Transplantation. 2012;94(1):22. 